\title{
Modelling the Impact of RCEP Agreement on the Economic and Trade Environment of Beijing
}

\author{
Yuanqing Liu, ${ }^{1}$ Xiongying Chen, ${ }^{2}$ and Yuan Tian $\mathbb{D}^{1}$ \\ ${ }^{1}$ Business College, Beijing Union University, Beijing 100025, China \\ ${ }^{2}$ School of Biochemical Engineering, Beijing Union University, Beijing 100025, China \\ Correspondence should be addressed to Yuan Tian; yuan.tian@buu.edu.cn
}

Received 21 August 2021; Revised 28 September 2021; Accepted 12 October 2021; Published 12 January 2022

Academic Editor: Daqing Gong

Copyright (C) 2022 Yuanqing Liu et al. This is an open access article distributed under the Creative Commons Attribution License, which permits unrestricted use, distribution, and reproduction in any medium, provided the original work is properly cited.

As a national economic, political, and cultural center that ranks first in terms of openness to the outside world, the signing of the RCEP agreement has undoubtedly brought a series of opportunities and challenges to Beijing. Based on the analysis of the two main features embodied in the RCEP agreement, this paper precisely analyzes the areas where the RCEP agreement has a key impact on Beijing's economy and trade and points out the opportunities and challenges brought by the RCEP agreement to Beijing's economic and trade development.

\section{Introduction}

1.1. RCEP Is a Dual Trade Agreement Driven by Market and System. At the market level, RCEP is a free trade agreement based on a mature Asian production network and close intraregional trade, so the focus should be on the economic and trade relations and industrial structure between Beijing and RCEP member countries. The member countries in the RCEP agreement form the largest combination of intraregional trade in East Asia, which is dominated by developing countries, many of which have weak economies of their own and export bulk commodities, and also most of the export enterprises are resource-intensive. The pattern of division of labor within the East Asian region is characterized by vertical integration, supplemented by horizontal integration; especially trade in intermediate goods has become the most important component of international trade within the East Asian region, which is also reflected in the large number of materials, parts, and semifinished products circulating between Japan, China, South Korea, and ASEAN. These materials, components, and semifinished products are mainly exported to North America and the EU after final assembly in China and ASEAN [1]. The RCEP covers the entire East Asian product market, and through the reduction of tariff and nontariff barriers among member countries, a unified market will be established, which will facilitate the optimization of production markets, deepen intraregional trade, support Beijing's deep participation in the global value chain, cultivate new competitive advantages in foreign trade, and help Beijing enterprises further develop the East Asian market.

At the industry level, RCEP will also force the transformation and upgrading of relevant domestic industries through the competitive effect brought by the big market and promote the high-quality development of the domestic economy. Demand puts a higher demand on supply. While promoting the upgrading of domestic consumption, RCEP needs to improve the quality of domestic goods and services from the supply side. While meeting domestic demand, we also need to build a high-quality international brand to meet overseas market demand. By placing domestic enterprises in a more challenging competitive environment, RCEP forces domestic industries to get rid of huge labor supply and resource advantages and replace them with the development of high-quality output [2].

At the institutional level, RCEP includes topics such as e-commerce, preentry national treatment for investment, government procurement, competition policy, etc. Although such topics have been covered in the bilateral FTAs signed by China, the negotiation of RCEP means that China will 
further open its market at a huge regional level for the first time, and RCEP will improve the level of opening at the institutional level in China. Therefore, the focus should be on the open market access system in the RCEP agreement, especially the broadening of the access system for trade in services, which has a positive contribution to reforming the market regulatory system, optimizing the business environment, liberalizing market access, and improving investment promotion and protection. Policy provisions in professional services, communication services, construction and its related engineering services, distribution services, education services, environmental services financial services, environmental services financial services, health-related services, and social services tourism services and other 12 major categories of services, excluding special instructions, are not restricted. The terms and conditions of the services trade among the member countries have achieved a high level of openness commitment. As a city dominated by trade in services, the signing of RCEP will undoubtedly bring huge advantages to Beijing. More financial resources, scientific and technological resources, and educational resources will come in with the exchange and communication between countries, which will improve the level of scientific and technological resources and educational resources, creating a better environment and attracting more enterprises and talents to form a more virtuous cycle. At the same time, it is of great benefit for the cultural industry with Beijing characteristics, which has the opportunity to show China's cultural soft power to other partners in the region through the Beijing window.

\subsection{RCEP Is an Agreement with a Diverse Membership} Structure. Compared with other FTAs, RCEP as a new type of FTA, covers 15 member countries with a population of about 2.3 billion, accounting for $30 \%$ of the global population and a total GDP of more than 25 trillion U.S. dollars. RCEP is the world's most involved in the population, the most diversified membership structure, and the largest development potential of the FTA. RCEP member countries have different international status, different stages of development, different industrial structures, and different national conditions. So the differences of RCEP member countries in economic and trade indicators are enormous. For example, in terms of GDP per capita, Singapore's GDP per capita in 2019 was $\$ 56,679.16$, ranking first among the 15 countries, while Myanmar, ranked last, had only $\$ 1,539.54$. Such a large difference in economic development is due to the different industrial structure development within its countries. The difference in industrial structure and the gap in industrial competitiveness can enable Beijing and the regional industrial development of RCEP member countries to form an overall development strategy with complementary advantages, staggered development, and mutual promotion. By choosing industries and enterprises that enhance the local economic and trade environment, investment attraction helps Beijing's local economic development and expands Beijing's export-oriented economic advantages.
At the same time, from the perspective of BeijingTianjin-Hebei synergistic development, the deep complementarity between Beijing and RCEP member regions is also conductive to the Beijing-Tianjin-Hebei FTA cluster to carry out differentiated exploration and increase the opening-up efforts, play a leading role in the development of Beijing, Tianjin, and Hebei with their own characteristics, and strengthen the synergistic linkage of national industrial clusters and urban industrial clusters.

\section{Main Impacts of RCEP Agreement on Beijing's Economic and Trade Environment}

2.1. Trade Creation Effect Provides Optimal Allocation for Beijing from "Resource Concentration" to "Function Deconcentration". Regional economic integration can bring obvious trade creation effect; i.e., the source of products is shifted from national producers with higher resource consumption to producers in member countries with lower resource consumption. The allocation of resources through free trade optimizes the allocation of resources and increases the welfare level of the integrated region. After the signing of RCEP, the mutual elimination of tariff and nontariff barriers among member countries facilitates the formation of a large unified market and brings fresh vitality of goods. The resources gathered in Beijing are abundant but very redundant and not very specialized. Therefore, the decentralization of non-Beijing functions can play a better role in this agreement: the transfer of commodities that Beijing does not specialize into other regions, the transfer of resources that have been optimized for allocation to the Beijing area, and the improvement of the professionalism and production efficiency of its local enterprises. The city's sustainable development capacity and scientific and technological innovation power will be improved by developing and improving in the process of decentralization and adjustment.

2.2. Trade Transfer Effect Is Conducive to Accelerating the Upgrading of Beijing's Service Industry. The signing of RCEP will lower customs tariffs and taxes, allow more cost-effective resources to enter, and prevent other countries from monopolizing a single commodity; RCEP will have a positive impact not only on the Beijing Free Trade Zone, but also on all 21 free trade zones in China. However, compared to the other 21 free trade zones in China, Beijing does not have a clear advantage in terms of commodity economy. The trade diversion effect will allow primary processed products and labor-intensive goods to be moved outside of Beijing, which will help improve resource utilization and generate tax revenue and profits. Beijing is an industrial structure dominated by a service economy. The share of tertiary industry is over $70 \%$, but Beijing is still developing foreign service trade based more on products in the traditional way. Under the framework of RCEP, there will definitely be a substantial promotion of the FTA between China, Japan, and Korea, and the FTA between China and ASEAN, which undoubtedly puts forward higher requirements for the transformation of Beijing's service industry. Therefore, the 
trade transfer effect brought by RCEP regional economic integration is conducive to the vigorous development of the service industry in Beijing and further promotes the upgrading of Beijing's service industry.

The digital economy industry needs to take advantage of business district gathering and technological innovation more than other industries. Beijing's digital economy currently accounts for more than $50 \%$ of the city's GDP. Beijing is one of the regions with an extremely developed digital economy that relies on the population's use of technology, with its advantages of external economy and immediacy. Especially at the time of the new crown epidemic, distance teaching and education for teachers, remote work for office workers, online shopping without leaving home, and delivery of contactless takeaways undoubtedly show the huge potential of cross-border e-commerce as well as the digital economy. According to the "Beijing Municipal Action Plan for the Innovative Development of Digital Economy (2020-2022)," by 2022, the added value of Beijing's digital economy will account for $55 \%$ of the regional GDP, and such a high percentage of GDP can take the lead in exploring the cross-border flow of data that is expected to provide a "Chinese solution" for the world, forming agglomeration of Beijing's digital economy industry, and will expand the economy of scale effect. The economic effect of scale brought by RCEP's regional economic integration can promote the development of digital economy industry, thus innovating the development environment of digital economy, enhancing the international competitiveness of digital trade, encouraging the development of new digital economy models, and exploring the construction of international information industry and digital trade port. The RCEP regional economic integration can promote the scale development of digital economy industry, thus innovating the development environment of digital economy, enhancing the international competitiveness of digital trade, encouraging the development of new models of digital economy, and exploring the construction of international information industry and digital trade port.

\section{Research Methodolgy: Analysis of the Advantages of the RCEP Agreement for Beijing's Economic and Trade Development}

\subsection{The RCEP Agreement Will Enhance Beijing's Unique} Comparative Advantage of Location Conditions. Beijing is at the center of the Bohai Sea Rim, the golden coast of China's northern coast, and plays an important role in China's coastal development strategy of opening up to the outside world. With more than 40 ports, the Bohai Rim constitutes the most dense port cluster in China and is rich in resources having abundant marine resources, mineral resources, oil and gas resources, coal resources, and tourism resources. Therefore, Beijing should focus on the geographical resource advantages of convenient transportation and rich resources in the future, so that the signing of RCEP can provide strong support for the supply of Beijing's commodities.
3.2. RCEP Agreement Will Highlight Beijing's Rich Educational, R\&D, and Cultural Advantages. Beijing is the most educated and culturally developed city in China, and it is the city with the most intellectual resources in China. It is the region with the highest concentration of scientific and technological, financial, and international business forces in China. There are 67 national key laboratories and national engineering research centers in Beijing, and 3961 headquarter enterprises. At the same time, it has a modern and relatively complete infrastructure, abundant human resources, and strong research and development and innovation capabilities, which attracts a large number of multinational companies to invest in it. In recent years, international multinational groups have set up holding companies and regional headquarters in Beijing. Beijing is an important hub for political, economic, postal, communication, and information connections between countries, and the RCEP member countries, which cover one third of the world's population, can bring a huge talent market to Beijing. Therefore, Beijing should focus on education, R\&D, and culture to attract a large number of professional talents to focus on Beijing's four central functions and continuously improve its professional strength. At the same time, professional talents will play a leading and spearhead role, which will inevitably promote the progress of technology and breakthroughs in the financial industry, forming a two-way cycle between high-quality enterprises and highly talented people.

\subsection{RCEP Agreement Will Expand the Advantages of the Three} Large Areas of Beijing FTA Conditions. After the signing of RCEP, enterprises from outside the region enter a country, then it means entering the whole region, the market and space will grow greatly, and, at the same time, they will further expand the economic radiation effect and siphon effect of each province's free trade zone. The Beijing FTZ mainly covers three zones: science and technology innovation zone, business service zone, and high-end industry zone. The choice of the low point of the three zones is based on the characteristics of the industrial development of each zone and the planning of their own development advantages. The Science and Technology Innovation Zone covers Zhongguancun Science City. Zhongguancun is known as China's Silicon Valley, which was established more than 20 years ago. With years of precipitation and accumulation, it has become an industrial park with a developed software and information service industry and a high capacity for technological innovation. The business service area is located in the embassy area, which facilitates cross-border communication and international relations. It provides a good environmental foundation for the development of commerce and trade. The high-end industrial zone is connected to the Daxing zone, where the Daxing Airport was built. Beijing Daxing International Airport is a "double hub" and has been successfully selected as an airport-type national logistics hub. The convenient transportation environment provides a good material basis for cross-border e-commerce. Therefore, for Beijing, the superposition of the three FTAs' 
distinctive development directions and the RCEP agreement will help enhance the negotiating power and attractiveness of the whole region, increase the overall negotiating power of the whole region, enhance the investment appeal, and improve the trade conditions.

\section{Results and Discussion: Challenges of the RCEP Agreement to Beijing's Economic and Trade Development Analysis}

4.1. High-Level Professional Type Talents Are More Fiercely Grabbed. After the signing of RCEP agreement, Beijing not only faces direct competition from domestic cities such as Shanghai, Shenzhen, and Hangzhou in terms of talents and policy resources, but also faces fierce competition from global superclass regions such as Tokyo and Seoul, which are RCEP member countries. At present, Beijing's R\&D investment structure is still not reasonable, with low enterprise investment. Less than $40 \%$ of the total social R\&D expenditure in Beijing is invested by enterprises, far below the level of more than $60 \%$ in developed countries, and also below the level of $60 \%$ in Shanghai and more than $90 \%$ in Shenzhen; the intensity of enterprise $\mathrm{R} \& \mathrm{D}$ investment is less than $1 \%$, far below the average level of $4 \%$ in countries with stronger innovation capacity [3]. The signing of RCEP not only has a positive effect on the Beijing Free Trade Zone, but also brings great potential to all 21 free trade zones in China. However, compared to the other 21 free trade zones in China, Beijing has more high-tech talents, and the competition pressure is huge. In such a high-pressure situation, it is very easy for talents to emigrate or to choose other cities directly.

4.2. The Region's Industries Are Facing More Severe Competition. RCEP agreement will bring a series of excellent foreign capital. The country's specific goal for opening up to the outside world, as proposed in the 14th Five-Year Plan, is to "adhere to the implementation of greater scope, wider fields, and deeper levels of opening up to the outside world, rely on the advantages of our large market, promote international cooperation, achieve mutual benefits and winwin results, and strongly support opening up to the outside world." In 2020, China implemented the Foreign Investment Law, while actively optimizing the business environment and opening the country's doors to welcome foreign companies. But attracting foreign investment is supposed to be a double-edged sword at the same time, which will form a huge pressure on the immature industries in the region. Enterprises that have not yet gone out in the Beijing incubation base, due to immaturity of technology, operation, and other factors, are very vulnerable to competition for resources, squeezing out, and even bankruptcy and extinction by foreign companies that have long been experienced in the market.

4.3. Industry Cluster Maturity and Industry Supporting the Urgent Need to Significantly Improve. At present, Beijing has just established a free trade zone, and three large zones have just been listed. The maturity of industry clusters is still at a relatively low stage. Compared to the maturity of other free trade zones that have been established for many years, Beijing is far behind in terms of supporting industrial facilities, training professional talents, and innovation of institutional environment. For example, in the high-tech fields of aerospace technology and medicine, the lack of patented technology development, or corresponding technical talents, even though the hardware facilities for research and development have been in place for a long time, the soft strength is not strong, the industry is not systematic, and the degree of clustering is not high enough, which still affects its production efficiency.

SWOT analysis of RCEP's impact on Beijing's economic and trade environment are shown in Table 1.

\section{Conclusions and Recommendations}

5.1. Innovative Talent Mechanism to Attract the Inflow of Professional Talents. The signing of RCEP means that Beijing's internationalization has increased and has injected a strong agent for Beijing's economic development, but at the same time, a large supply of professional talents is needed in the process of Beijing's accelerated economic development. Therefore, Beijing should accelerate the innovation of talent system and mechanism to cultivate business management talents who are familiar with international trade, investment, and finance, as well as scientific and technological talents with independent innovation ability, good scientific ethics, and professional knowledge level. The signing of RCEP also provides a more convenient channel for the introduction of domestic and foreign first-class talent professionals. Beijing can attract talents through the corresponding settlement policy, as well as personal income tax exemption policy and other welfare benefits. For the introduction of foreign talents, they will enjoy the same treatment as nationals and provide education and work opportunities for their family members' spouses and children.

5.2. Timely Prevention to Resolve the Risks That May Be Brought by Opening. The signing of the RCEP agreement will certainly bring about a collision of cultures, policies, and technologies among various countries. A series of new issues and debates on intellectual property rights, land use, etc. will continue to emerge. The government and enterprises should be proactive and "one step ahead" to avoid disputes by taking into account past investment experiences. At the same time, the government should actively resolve disputes and provide reasonable solutions, reflecting the government's regulatory role and function. For disputes that require arbitration and judicial proceedings, choose arbitration institutions and recognized international certification bodies in advance.

5.3. Reduce Industrial Pollution and Enhance the Environment to Share the Blue sky of Science and Technology. The zero tariff orientation of the RCEP agreement will certainly accelerate the flow of low value-added products from the regional 
TABLE 1: SWOT analysis of RCEP's impact on Beijing's economic and trade environment.

\begin{tabular}{ll}
\hline Advantage $(S)$ & Threats $(\mathrm{T})$
\end{tabular}

The development of naive enterprises: Due to the immaturity of Position advantage: Beijing is located in the center of the Bohai Rim technology, operation and other factors, enterprises are easy to be region with numerous ports around it

Resource advantages: rich educational resources, research and development policy, and a good business environment, foreign investment enterprises, rich historical and cultural background. At the same time for talent gathering highland

Advantages of service trade: the tertiary industry as the pillar, the development of service; Business trade industries such as financial services, digital economy, electronic services, system and environment innovation are not business, scientific and technological services

Weaknesses (W)

The industry in this region is facing more severe competition: the policy of opening to the outside world, and a good business environment, foreign enterprises have entered. If local firms are not strong enough to resist a run on them, they face the risk of bankruptcy

The maturity of industrial cluster needs to be greatly improved: the industry is not systematic in terms of supporting industrial facilities and institutional environment innovation, and the low cluster level will affect its production efficiency

countries. Although Beijing will continue to transform and upgrade its industrial structure, it should also pay close attention to more pollution-indexed products, such as laborintensive products, primary processing products, and raw materials, from the countries in the region, from going out to coming in. Therefore, special attention needs to be paid to the pollution and emissions brought about in the opening up to the outside world to mitigate the corresponding negative externalities of environmental pollution. The fundamental method to reduce heavy industry to enhance high valueadded products is the innovation of science and technology and increasing the efforts of science and technology to control the environment. Technology and technology drive industrial development, improve the efficiency of factory operations, improve product profitability, and share the blue sky of technology.

\subsection{Implementing Lenient and Strict Governance and} Strengthening Follow-Up Supervision Measures. After the signing of RCEP, the market access threshold can be lowered to reduce the cost of foreign enterprises to enter the region. However, at the same time, in order to ensure the economic security and development of the region, follow-up regulatory measures should also be strengthened, such as strict control of drug safety in the pharmaceutical industry jointly with the Drug Administration and other departments, late acceptance in engineering construction, changing the process model, strengthening the management of the process in the later stages, highlighting the supervision mechanism, and preventing the process risk. competed for resources by foreign-funded enterprises with market experience, and even go bankrupt. Perish

Talent scramble: not only Beijing, other provinces and the world also need high-level professional talents

Opportunities (O)

Reduce tariff: benefit Beijing area high-tech product export. And imports of products with high comparative advantages to improve people's welfare The entry of foreign enterprises: improve the quality of local economy, bring talents and resources, and form healthy competition locally

Developing characteristic economy: Beijing has just established a free trade zone, which can bring new resources, technology and vitality to the science and technology innovation zone, business service zone and high-end industry zone

broader platform for Beijing to innovate the complementary model of "digital economy + expo" as the RCEP will help Chinese Internet companies to develop overseas, and the marginal effect of the integrated market for e-commerce and digital economy will increase. Beijing is a place where major conferences, exhibitions, and fairs gather. The zero tariff clause in RCEP will benefit more consumers and attract more enterprises to explore the market in Beijing, and with Beijing's positioning to vigorously develop digital trade and e-commerce, it will extend the sales of enterprises to online and broaden the sales channels on e-commerce platforms such as Taobao and Jingdong, giving a strong impetus to the regional economy, and invite enterprises from RCEP member countries to exhibit and participate in the conference to closely combine the resources and market advantages of the 10 ASEAN countries with the capital and technology advantages of other RCEP member countries on a larger scale to serve Beijing, to integrate the supply chain of industrial chain in a wider scope, to make full use of "two markets and two resources," and to serve the new development pattern with the domestic circulation as the main body and the domestic and international circulation promoting each other.

5.6. Create a Digital Economy Industrial Park plus High Technology Service Clusters. The digital economy is a unique advantage of Beijing FTA. With the signing of RCEP, Beijing's digital economy advantages will be further amplified, and corresponding policies should be accelerated to create a digital economy industrial park + high-tech service cluster. In general, under the current domestic and international double-loop pattern, the international integration of digital economy and the cross-border safe flow of data still 
face many challenges, mainly related to the liquidity of data production, pricing of data consumption, uncertainty of cross-border data flow, security issues, and so on. Beijing should introduce a series of measures in this regard, actively promote the construction of a national digital economy pioneer and demonstration zone, and strive to build an international big data exchange, which will be an important pillar for China to break through international digital changes and promote the globalization of China's digital economy in the future [4]. Appropriate preferential policies are introduced through the Digital Economy Industrial Park to introduce Internet platforms, Internet+, 5G applications, big data, cloud computing, cyber security, etc. and attract more digital enterprises to the Beijing FTZ Internet Digital Economy Industrial Park. The digital industry economic park is a cradle focusing on the growth of major outstanding enterprises, while playing an incubating as well as leading role for tiny enterprises. The park provides public services, financing services, talent services, and policy support for small- and medium-sized enterprises to foster "three new and one high" high-growth enterprises and technologybased small- and medium-sized enterprises, take advantage of the digital economy to build big data centers and smart cities. At the same time, through forums, annual meetings, and other forms, gather more resources, elements, accelerate the construction of the inspection and certification system, and promote the national public inspection and certification service platform demonstration area and the national inspection and testing high-tech service cluster project landing. Beijing will be made into a digital economy industrial park and high-tech service cluster, while the excellent experience, scientific research results, and practical methods will be promoted nationwide, leading the national economy to prosper together.

5.7. Formation of "RCEP Regional Integration + City Cluster Superposition" Effect. The economic effect of regional economic integration formed by RCEP should be superimposed with the economic effect of city clusters to radiate the Beijing-Tianjin-Hebei region and lead the regional economic development. Beijing-Tianjin-Hebei synergistic development is one of the three national strategies, aiming at the synergistic development of Beijing-Tianjin-Hebei as a whole, with the Beijing region as the leader, taking the lead in the sprint run, and to build a world-class city cluster with the capital as the core to create a new support belt for China's economic development. At present, the integration of urban transportation in Beijing, Tianjin, and Hebei has taken initial shape, but there are still some barriers in information sharing and information disclosure. Therefore, barriers in administration, transportation, and information should be broken down in the construction of city clusters in the degree of openness brought by RCEP, and the free flow and equal competition among provinces and cities and various market players in the region should be strengthened by removing these barriers. In all aspects of talent and resources, including social security, medical education, and public services, we promote a high degree of institutional and mechanical alignment, so that the economy, market, technology, and resources can flow scientifically and rationally with each other. With Beijing as the core growth pole of the Capital Economic Circle, we will promote its excellent cooperation methods and business models, play a leading and demonstration role, and replicate and develop them in the "two wings" according to local conditions, enhance regional synergy and overall regional competitiveness, and develop and prosper together [5-11].

\section{Data Availability}

The data used to support the findings of this study can be accessed at http://fta.mofcom.gov.cn/rcep/rcep_special. shtml http://fta.mofcom.gov.cn/ http://www.beijing.gov. $\mathrm{cn} /$ http://www.beijing.gov.cn/fuwu/lqfw/ztzl/zmq/index. html.

\section{Conflicts of Interest}

The authors declare that they have no conflicts of interest.

\section{Acknowledgments}

This research was supported by Beijing Municipal Education Commission Social Science General Project (Research on the Interactive Mechanism of Urban Sprawl and Eco-efficiency of Beijing-Tianjin-Hebei Urban Agglomeration) SM202011417010), Beijing Xi Jinping New Era Research Center for Socialism with Chinese Characteristics Project (Beijing Social Science Foundation Project) Beijing-Tianjin-Hebei carbon emission key driving mechanism and coordinated emission reduction policy design research (21LLGLC038), and Humanities and Social Science Research General Project of the Ministry of Education (China's Carbon Emission Forecast, Emission Reduction Path and Industry Responsibility Distribution under the Carbon Neutral Target) (21YJC630127).

\section{References}

[1] P. Liqun, "The pace of Asia-Pacific regional economic integration-with RCEP at the center," Asia-Pacific Security and Maritime Studies, vol. 6, pp. 111-124, 2020.

[2] F.-Q. Lin, M. Liu, and Y. Lv, "Regional economic integration strategy under the new development pattern of double cycle: the potential impact of RCEP," Journal of Chang'an University (Natural Science Edition), vol. 23, no. 1, pp. 80-92, 201.

[3] Y. Liu, Three Major "Tests" to Be Met to Build a Digital Economy, 21st Century Business Herald, Guangzhou, China, 2020.

[4] A. Burinskiene and D. Romaskeviciene, "Online shoppping and consumer protection," Journal of System and Management Sciences, vol. 8, no. 1, pp. 1-22, 2018.

[5] L. Liu and M. Zhang, "How far is Beijing from being a world city? (Previous part)," Investing in Beijing, vol. 6, pp. 22-26, 2018.

[6] F. B. Hammad, "The vision 2030: corporate governance perspective in Saudi arabia," Journal of System and Management Sciences, vol. 9, no. 1, pp. 48-68, 2019. 
[7] J. B. Kim, "Implementation of artificial intelligence system and traditional system: a comparative study," Journal of System and Management Sciences, vol. 9, no. 3, pp. 135-146, 2019.

[8] S. Jeong and I. Choi, "Cognitive bias in decision making according to change of tax policy: an exploratory study," Journal of System and Management Sciences, vol. 9, no. 4, pp. 127-137, 2019.

[9] D. Chowdhury, P. Gharami, and J. Akter, "implementing advanced software in construction project management and control," Journal of Logistics, Informatics and Service Science, vol. 6, no. 1, pp. 87-105, 2019.

[10] L. L. Zhang and H. K. Kim, "The influence of financial service characteristics on use intention through customer satisfaction with mobile fintech," Journal of System and Management Sciences, vol. 10, no. 2, pp. 82-94, 2020.

[11] F. Georgescu, B. Cozmâncă, A.-M. Cazacu, and A.-M. Cojocaru, "fiscal and income incentives trigger imbalances in a partly functional market economy," Economic Computation \& Economic Cybernetics Studies \& Research, vol. 54, no. 2, pp. 5-22, 2020. 